\title{
Chapter 18 \\ Ethics, Economic Organizations, and Human Flourishing: Lessons from Plato and Aristotle
}

\author{
Benedetta Giovanola and Arianna Fermani
}

\begin{abstract}
This paper seeks to show the importance of the thought of Plato and Aristotle for today's economics and business, especially in the light of the global financial and economic crisis. Our aim is twofold. On a general level, we illustrate the intrinsic connection between ethics and economic processes and organizations. On a more detailed level, we describe several specific values and principles highlighted by both Greek philosophers that can play a fundamental role in today's organizations and business leadership. To this end, the first two sections examine Plato and Aristotle's reflection on economics and riches and analyse how they relate to human flourishing (Sect. 18.2) and social justice (Sect. 18.3). Sect. 18.4 and Sect. 18.5 focus on several specific values and principles examined by Plato and Aristotle that can be key in enabling economics to foster the good of the individual and society. More specifically, Sect. 18.4 describes the notions of virtue, selfmoderation and excellence, whereas Sect. 18.5 focuses on self-knowledge and wisdom, which are strictly interrelated. The concluding section shows how the values and principles described in the previous sections can play a fundamental role in today's economic organizations and business leadership.
\end{abstract}

\subsection{Introduction}

This paper examines some major lessons from ancient Greek philosophy, more specifically that of Plato and Aristotle, in order to show how important they are for today's economics and business, especially in the light of the global financial and

\footnotetext{
B. Giovanola $(\triangle)$

Department of Philosophy, University of Macerata, Macerata, Italy

e-mail: giovanola@unimc.it
}

\author{
A. Fermani \\ Department of Philosophy, University of Macerata, Macerata, Italy \\ e-mail: arianna.fermani@unimc.it
}


economic crisis. The underlying idea is that adoption of the thought of Plato and Aristotle as a theoretical framework can provide a sound ethical foundation for economics and business, a particularly urgent need today, when economic activity has ever greater structural effects on human beings, with repercussions that go far beyond economics to areas such as the constitution of personal identity and interpersonal relationships.

A reform, then, is needed, especially because contemporary developments of capitalism have compromised the continuance of the original values and "anthropological types" that have enabled it to function, substituting them with values that are increasingly quantitative. In order to pursue such a reform, we need an ethical foundation for economics and business, and more human models.

In this regard, it is interesting to note that some recent attempts to conceive of more human models in economics and business use Aristotle's thought (or, more in general, virtue ethics) as a starting point (Collins 1987; Crockett 2005; Koehn 1995; Meikle 1996; Solomon 2004). However, these studies often isolate some specific issues of Aristotle's thought and then apply them to specific economic concerns, whereas it would be important to understand and contextualize Aristotle's economic theory within his ethical thought as a whole. Instead, for Plato, not enough attention has been paid to his thought in connection to economic and business matters: this lack of interest may be due to a quite traditional interpretation that portrays Plato as an ascetic philosopher who strongly rejects exterior well-being in favour of exclusively interior well-being, and whose thought thus would hardly be expected to help us in tackling matters of economics and business.

In our paper, by taking Plato and Aristotle's thought as our theoretical framework, we pursue a twofold aim.

On a general level, we seek to show the intrinsic connection between ethics and economic processes and organizations, in terms of fostering human fulfilment (the individual level) and promoting social justice (the collective level).

On a more detailed level, we describe several specific values and principles examined by both Greek philosophers that can play a fundamental role in today's economic organizations and business leadership.

In order to pursue this twofold aim, the paper is divided into the following sections.

Section 18.2 focuses on Plato and Aristotle's reflection on the notion of economic and material wealth and analyses its relationship with the notion of human flourishing (eudaimonia). Thorough analysis of the lemma ploutos (riches) in Plato and Aristotle's works shows that both philosophers recognise the value and importance of riches and material well-being, but at the same time interpret them in an instrumental (and not finalistic) way. In other words, according to Plato and Aristotle, wealth is not an end unto itself, but rather a means towards human fulfilment and flourishing; accordingly, economics is instrumental to ethics in the degree to which it can provide and manage material well-being, and is praiseworthy only insofar as it is practiced with virtue and leads to a good life.

Section 18.3 further develops the intrinsic connection between ethics and economics, by shifting attention from the individual (each human being's flourishing) to the social-collective dimension of economics. In particular, we argue that according to Plato and Aristotle, economics is strictly linked to the promotion of social justice: 
in other words, economics is a means toward the flourishing not only of the individual, but also of the community. More specifically, we argue that social justice requires both the capability to engage in fair relationships with the others, and the responsibility for our actions and their effects on others: both elements are fundamental in order to preserve the ties of reciprocity on which every society relies.

Sections 18.4 and 18.5 focus on some specific values and principles examined by Plato and Aristotle, that can be key in enabling economics to foster the good of the individual and society. More specifically, Sect. 18.4 focuses on the notions of virtue, self-moderation and excellence, whereas Sect. 18.5 describes self-knowledge and practical wisdom, which are strictly connected to each other.

The concluding section shows how the underlying framework, as well as the values and principles sketched in the previous sections, can play a fundamental role in today's economic processes and models, especially in the light of the global financial and economic crisis, and can promote more humanised business and more humane economic organizations. Here also the role of practical wisdom and "wise business leaders" is highlighted as a key feature of economic organizations oriented towards human fulfilment and the promotion of social justice.

\subsection{Plato and Aristotle on Economics, Riches and Human Flourishing}

Blessed are the poor was not within the Greco-Roman world of ideas (Finley 1973, p. 38)

The term ploutos (riches) occurs frequently, ${ }^{1}$ both in Plato, who "was acutely aware of issues about the significance of poverty and wealth in human life" (Lötter 2003, p. 192), - and in Aristotle.

We find 81 occurrences of the lemma $\pi \lambda$ ov $\tau$ os in Plato's works, while the same term occurs 110 times in Aristotle's. In both cases, the notion of riches is seen quite consistently, and appears in all the works of the two philosophers, from the one traditionally considered "young" (for instance, Plato's Euthyphro and Aristotle's Topics), to other, certainly "late", works (such as Plato's Laws).

On the value and the importance of riches and material well-being, neither of the two philosophers, in accordance with the general judgement of antiquity about wealth, seems to have any reservation. ${ }^{2}$ For Plato, in fact, riches is a good and poverty (penia), on the contrary, is an evil to fight, because, as we read in Laws XI, 919 C 2, poverty "by means of pain plunges it [the soul] into shamelessness". For the Philosopher, in fact, "lack of money, poverty, makes it very difficult to live a moral life. Adequate resources to escape poverty thus seem a prerequisite for living Plato's moral life" (Lötter 2003, p. 192).

\footnotetext{
${ }^{1}$ See Radice and Bombacigno (2003; 2005).

${ }^{2}$ For a deepening of this issue see, for instance, Hadreas (2002). On the value and the importance of economics in Plato, see Schofield (1993).
} 
Aristotle, for his part, states that nobody can deny that "victory, honour, wealth, and the other good and pleasant things of the same sort" (Nicomachean Ethics VII, 5, 1147 b 29-30) are choice-worthy, and asserts that nobody can be blamed for desiring and loving these goods (Nicomachean Ethics VII, 6, 1148 a 25-27).

On this specific topic, therefore, the two philosophers seem to share the same opinion. This closeness, moreover, is corroborated, for instance, by Republic I, 331 A 7-8, where Plato writes that "the possession of wealth is of most value", while a few lines later he reminds us that "the possession of property contributes not a little" (Republic I, 331 B 7). For Plato, therefore, wealth, in itself, is certainly a good, just like such goods as beauty, justice ${ }^{3}$ and medicine.

Wealth, therefore, is undeniably a good, both for Plato and Aristotle. And this positive conception of riches is typically Greek. In fact, "underpinning the positive Greco-Roman judgement of wealth was the conviction that among the necessary conditions of freedom were personal independence and leisure" (Finley 1973, p. 40).

At the same time, however, both philosophers agree that the peculiarity of riches lies in the fact that it can be used well or badly. This is why in Plato we can find, at the same time, assertions about the importance of riches, and statements like the following ones:

All the gold on earth, or under it, does not equal the price of goodness (Laws V, 728 A 3-4).

To his children it behoves a man to bequeath modesty, not money, in abundance (Laws V,

729 B 1-2).

At first glance, it could seem that these two conceptions of riches contradict each other, but Plato never denies the value of riches for human life. Wealth is important, and its power in human life cannot be denied or diminished.

The crucial point for Plato (and also for Aristotle) is that while wealth is an essential good for human life, there is something more important than wealth itself: the ability to use it well.

In order to clarify this fundamental issue, it is necessary to distinguish between possession (ktesis) and use (chresis). In fact, "a person may possess but not use good things; and if she does not use the goods she possesses, she will not necessarily benefit from them; and if she does not benefit she will not thereby be happy. For example, if one had food but did not eat it, or a carpenter had tools but did not use them, one would not be benefited by them" (Santas 2001, p. 34).

It is exactly in this sense that Aristotle, for instance in Great Ethics I, 2, $1183 \mathrm{~b}$ 20-30, distinguishes between three groups of goods: some goods are honoured, others are praised, while others again (among them riches) are only potentially goods. Wealth, in fact, is a very particular good and its specificity lies in the fact that it must be used well. Only if this good is used well is it really a good. On the contrary, if it is used badly (and it is used badly by a vicious person, while it is used rightly by a virtuous person: "for of these the good man has the power to make good use, and the bad man power to make evil use", Great Ethics I, 2, 1183 b 29-30), it becomes an evil and a source of unhappiness. In fact, Aristotle points out that

\footnotetext{
${ }^{3}$ On the issue of justice in Plato (and Aristotle) see Sect. 18.3.
} 
"people have before now been ruined by wealth (dia plouton)" (Nicomachean Ethics I, 3, 1094 b 14-19).

Similarly, Plato reminds us that the possession of wealth, beauty and riches constitutes an important opportunity to live happily, and in Laws II, 661 B 5-8 he argues, referring to the goods, among them riches:

What you and I say is this-that all these things are very good as possessions (ktematai) for men who are just and holy, but for unjust they are (one and all, from health downwards) very bad.

Thus for a bad man, coming into possession of a sum of money could prove not only useless (as food appropriate for a healthy man is useless for an ill man, or as the ornaments of an uninjured man are useless for an impaired man), but also dangerous. It is dangerous because external goods are unstable. In fact, if they are not managed by phronesis they can reduce a rich life to poverty.

Thus, Aristotle states, wealth can be considered "a collection of tools" (Politics I, 8, 1256b, 37-38), and as such "it is only good as being useful, a means to something else" (Nicomachean Ethics I, 5, 1096a, 5-7).

Above all, riches should be a means to live well, that is - in Platonic and Aristotelian words - to lead a flourishing life. The ideal of human flourishing (eudaimonia) thus represents the end towards which any instrument - including riches - should strive. In this regard, the link between human flourishing and riches, and, more in general, between the "whole" (the good life) and its components (including riches) becomes increasingly significant, clear, and conceptually relevant. Consequently, economics, through which riches are provided and managed, is instrumental to human flourishing and embedded in an ethical foundation.

To sum up, we can state that from the Aristotelian and Platonic perspective, the nature of economics, which provides riches, is functional, not finalistic. In fact, as we will see in the following pages, the possession of riches must be linked with the strategic virtue of wisdom, in order to organize and manage them (i.e. the riches) and thus flourish, just as every human life needs to be guided by it in order to organize and manage all the goods and thus to flourish.

\subsection{Plato and Aristotle on Economics, Riches and Social Justice}

As we have seen, economics should serve the acquisition and management of a limited amount of goods, ${ }^{4}$ that is, those goods that are useful to the pursuit of human flourishing (eudaimonia). At the same time - Aristotle adds - the goods that constitute the "real riches" are those that are "necessary to live and useful to the community of the State or the family" (Politics I, 8, 1256b 26-30). This means that

\footnotetext{
${ }^{4}$ Actually Aristotle distinguishes between crematistics, which is aimed at providing goods, and economics, which is aimed at managing goods. The former is a part of the latter (see Aristotle, Politics, in particular Book 1, chapters 8-10).
} 
economic activity (and wealth) is not only instrumental to individual human flourishing, but should also serve a "common" purpose, and contribute to the good of the community in its major forms: the household (oikos, hence the term oikonimike, i.e. economics) and the city-state (polis), both characterized as cooperative units. Therefore, economics is also a necessary, albeit insufficient, instrument for preserving the community, because human beings both desire to live together (because they are political animals) and need to live together (because they need one another in order pursue and manage common interests). In fact, as Aristotle argues in his Politics:

Man is by nature a political animal. And therefore men, even when they do not require one another's help, desire to live together; (although) they are also brought together by their common interests in proportion as they severally attain to any measure of well-being. This is certainly the chief end, both of individuals and of states (Politics, III, 6, 1278b, 18-24).

More specifically, the collective and social dimension of economics is founded on the role that economic processes and organizations play in fostering social justice, which is also defined as "justice as reciprocity" (Nicomachean Ethics V, 5). In fact, according to Aristotle, economic processes and organizations have the important role of promoting fair exchanges among the members of a society, where there is a community (koinonia) of interests and people have different needs. In this framework, economic processes and organizations are good insofar as they contribute to the social goal of fair distribution, and become "against nature" (to use Aristotle's terminology in Politics) if they are oriented toward mere accumulation of material goods or riches: in the latter case, in fact, they would destroy the relationships of reciprocity and fairness on which every society is based.

Economics is very important in promoting social justice and, according to both Aristotle and Plato, justice is a fundamental virtue, one that connects human beings with one another. Justice is the "perfect virtue" because it is virtue in its fullest form: since it is directed toward others (and not only to ourselves), it is the form of the good in relation to others, the only virtue that can even be considered "the good of the others" (Nicomachean Ethics V, 1, 1129b 30 - 1130a 5).

In fact, justice requires that one thinks of oneself as a member of a larger community (the polis), and not as an isolated individual; in other words, it requires both the capability to engage in fair relationships with others, and the responsibility for our actions and their effects on others: both elements are fundamental in order to preserve the ties of reciprocity society relies on and through which community is preserved.

More specifically, economics can fulfil its function thanks to the mediation of money which is said to be both the tool and the "guarantee" of justice as reciprocity (Nicomachean Ethics V, 5, 1133b 12): money is a "substitute for needs", making it possible to "exchange needs", because it enables mediation among qualitatively different goods and meets the need to make such goods (quantitatively) equivalent, so that they can be exchanged through economic transactions. These transactions, in fact, allow the members of a community to satisfy their needs - which vary from individual to individual - and thus become self-sufficient. In other words, money was created and is useful because there is a community (koinonia) of interests and 
needs: since human beings seek to become self-sufficient but cannot satisfy all their needs alone, they must engage in economic transactions with other individuals, thus creating a community of interests and needs. At the same time, such a community exists only insofar as the members can obtain through a fair exchange what they do not possess but require. Money seeks to maintain fair exchange, and thus keep community bonds strong. Thus, economic processes, which are mediated through money, are to be understood within the framework of a theory of justice.

These conclusions lead to another reason Aristotle sharply criticizes the accumulation of money and, broadly speaking, the focus on material well-being and riches: they would threaten the basis of justice and co-existence by breaking the ties of reciprocity on which the polis relies. In other words, if riches and material wellbeing became the aim of economic processes and transactions, not only would individual human flourishing become impossible, but also the bond of reciprocity and fairness between community members would be shattered, undermining collective well-being.

This "social" limit to economics is also shared by Plato, who understands justice as both a virtue and a good, arguing that it has a very crucial role in the construction of the polis.

For Plato, justice, as elucidated so well by Santas (2001, p. 111), is what is strictly and structurally linked with the good life of the city and the individual: Plato's "defence of this highly cooperative social ideal is that it promotes most the good of all the citizens; and that this good is the development and exercise of the citizens' greater social capabilities, a functional and perfectionist human good".

To sum up, we can argue that according to both Plato and Aristotle, economics is good as long as it fosters individual human flourishing and social welfare; if it looses its twofold distinctive function, it turns into something "unnatural" that prevents human beings from flourishing and being members of a community. In other words, there are both individual and social limits to economics, and these limits ultimately refer to two main questions: (1). how should I live (and behave as an economic agent, as well) in order to lead a flourishing life?; (2). How should I live (and behave as an economic agent, as well) in order to contribute to the welfare of the society in which I live? These two major questions (Sen 1987) delineate the ethical and social boundaries of economics, as well as its ultimate value.

\subsection{Plato and Aristotle on Virtue, Excellence, and Self-Moderation}

The previous considerations show that economics should always have as its touchstone a fundamental ethical dimension that orients it to foster human fulfilment and promote social justice, namely, to build the good of the individual and society. If it is true that the good of society is strictly linked to justice and reciprocity, then the

\footnotetext{
${ }^{5}$ For a deepening of the link between justice and wealth in Plato, see Lötter (2003).
} 
supreme good of the individual consists in eudaimonia, as we have seen in Sect. 18.2.

However, while the last section examined the meaning and role of social justice, as well as its relationship with economics, we have not yet analysed the notion of eudaimonia and its distinguishing features; doing so will enable us to highlight some specific values and principles that can play a fundamental role in the capability of individuals to perform economic actions that are embedded in an ethical foundation and aimed at the pursuit of a good life.

Human flourishing or eudaimonia defines the "human good" - that is, the good which is proper to the human being - and "implies the possession and the use of one's mature powers over a considerable period of time", "the fulfillment of the natural capacities of the human species" (Cooper 1975, p. 89, n. 1).

A realized or eudaimon life, therefore, is a life in which all the potentialities have been actualized to their best, or, in other words, a life in which all the resources or capacities have been wisely managed. It means both "living well" and "acting well"; it is the good proper to the human being and towards which any human activity should be oriented. Eudaimonia can be understood both as "well-being" and as "good life", as a life objectively realized and as a life that subjectively realizes. A eudaimon person, in fact, for Plato and Aristotle, is one who has a ordered and well-composed life (i.e., a life in which every part is well organized in a "structured whole", in a holon, and not in a pan), and who draws pleasure from this life.

But there is another very important feature of eudaimonia. In fact, the good life, properly speaking, is a virtuous life. What, then, are virtues? According to Aristotle, virtues are those dispositions "by which a person becomes good and performs his/ her function well" (Nicomachean Ethics II, 6, 1106a, 22-24). More precisely, Aristotle states that virtue is "a disposition concerning choice, consisting in a medietas [a Mean] in relation to us" (Nicomachean Ethics II, 6, 1106b, 3611076a, 1): such a Mean, found as it is between two extremes, is evidently of a qualitative nature and, from the point of view of good, represents an optimum, or an excellence (Nicomachean Ethics II, 6, 1106b 22, where Aristotle defines virtue as "meson te kai àriston"). The virtuous action is indeed teleologically oriented towards excellence, towards the formation of a good character and the fulfillment of a good life (i.e. human flourishing or eudaimonia): therefore any specific human activity - and thus economic activity, as well - ought to be oriented by this telos (eudaimonia, indeed).

At the same time however, virtue is based upon self-moderation: even if it represents excellence from the viewpoint of the good, virtue is nonetheless a "Mean" between two extremes. This "Mean", as we have seen, is not of a quantitative but of a qualitative kind, and varies from individual to individual: it is a Mean "according to us" (pros emàs): in other words, each one needs to find his or her own Mean in order to fulfill his or her own potential in the best way.

To sum up, virtue and self-moderation are constitutive elements of human flourishing: only if they orient human activity (and thus also economic activity) do they allow human beings to fulfill themselves, striving for excellence. 
Now we can also better understand the reason economics should seek to acquire and manage a limited amount of goods. In fact, an ideal of virtue and self-moderation is at stake in such an understanding of economic affairs: (material) wealth is to be evaluated by how it contributes to a good and flourishing life, while only by working out the constitutive elements of a good and flourishing life can we identify what to demand from the economy (Giovanola 2009). According to such a perspective, economic affairs are not free-standing, and consequently, sound economic theories (and practices) cannot be defined by merely quantitative parameters, but need to be assessed by qualitative criteria, the most important being the opportunity for all agents to realize their own potential and thus to fulfill themselves in a virtuous and flourishing life.

In other words, economics becomes "unnatural" if it is aimed at accumulating excessive riches and thus becomes "measureless": in this case, economics is no longer directed toward the pursuit of a good life on the individual level, and destroys the ties of reciprocity on the collective-social level. However, it is important to emphasise that destruction of the ties of reciprocity is not only a "social" problem, but also an individual one, because it would limit the possibility for individuals to engage in fair relationships with others, and this possibility is itself an important element of human flourishing. In other words, separating individuals from their community also impacts their capability to flourish.

In fact, even if human flourishing is eminently individual (since it is proper to each and every individual and varies from individual to individual), it also entails a strong social dimension. The good life cannot be attained in isolation: according to Aristotle (and Plato), eudaimonia is deeply social, that is, it also depends on social relationships and friendship (philia). Moreover, another reason why eudaimonia cannot be realised apart from the communities we live in is that human beings need examples of real people who behave and form themselves in an excellent way, namely, people who act virtuously and excel in practical wisdom.

\subsection{Plato and Aristotle on Self-Knowledge and Wisdom}

In order to better define wisdom, it is important to focus on another distinctive element of eudaimonia, which is strictly linked to wisdom itself: self-knowledge. In fact, eudaimonia also requires a high degree of self-knowledge, as well as the possession of and the capability to use one's mature powers over a considerable period of time. This means that eudaimonia requires the development of our own potential and talents, which in turn demands both an environment that is conducive to human growth and fulfillment, and each individual's capability to identify the virtuous action and realize it.

In fact, for Plato and Aristotle, "a life can be poor not only because is insufficiently equipped with resources, but also because it has many resources but is unable to use them [...], because it does not succeed in managing them, or because it unilaterally flattens itself to the level of resources. One may accumulate a great 
deal, but have nothing, because one is incapable of keeping what one possesses" (Fermani 2006, p. 249).

This is why both Plato and Aristotle, as we have seen, argue that human flourishing depends not only on the possession of good things but above all on their correct use and management. According to the two Greek philosophers, only in this way it is possible to realize oneself and attain a good life.

For Plato and Aristotle, the good use of resources and their adequate management (and the correct placing of all the other goods inside the whole life) is made possible by the very crucial virtue of practical wisdom (phronesis): "if we aim at our own happiness, correct use of the goods of the inventory will depend on wisdom, that is, knowledge of what uses will bring us benefit and happiness" (Santas 2001, p. 35). Wisdom, in fact, is this knowledge of the uses of conditional goods that promotes human flourishing. Therefore, a use of good things, a use that will provide us fulfillment, depends on wisdom, so that we can argue that "none of the things ordinarily thought good are beneficial and bring us happiness unless they are used and used with wisdom" (Santas 2001, p. 35, italics added).

In other words, wisdom is the condition for wealth and, more in general, for the other goods - given that "wisdom is the condition of their goodness" (Santas 2001, p. 35). At the same time, according to both Plato and Aristotle, phronesis has another fundamental role with regard to the construction of a realized life. Wisdom, in fact, can also be identified (as it clearly emerges, for instance, in Plato's Charmides 167 A 1-7) with self-awareness or self-knowledge.

The topic of self-knowledge in Plato, Aristotle and, more in general, in ancient thought, has been the object of a great number of studies. ${ }^{6}$ Obviously, this very complex problem cannot be adequately explored in this paper, but its fundamental importance in the construction of a realized life cannot be understated. No life can flourish if it has many resources but does not use them rightly, as we have seen. But in order to use our resources well, and then to formulate winning strategies for life, it is first of all necessary that we know ourselves.

It is impossible to develop strategies or identify the course of one's life, or make oneself flourish, without knowing, above all, oneself, because wisdom cannot exist without self-knowledge and without - to a certain degree - identifying with it.

But, again, it is important to point out that a winning strategy is winning for me and for my particular life, given that, as Aristotle reminds us, human flourishing is always something particular and personal (Nicomachean Ethics I, 5, 1095 b 25-26), the measure of which must be modulated on the individual and on his or her always changing - features. In this sense, a "continuous creative use of the rules" is necessary, as is the development of a true strategy. And no eudaimonistic strategy can be the same as that of another because no human being has the same skills and the same inclinations as another, because the habits constructed by human beings

\footnotetext{
${ }^{6}$ See, for instance, North (1966). For a deepening of this topic see Napolitano Valditara (2012). See also Renaud (2012). On this theme, analysed in a more general perspective and with a theoretical approach, see Garret (1998).
} 
are not all the same but always "made to measure" ("the shoe that fits one person is narrow for another: there is no "life-formula" that fits everyone" wrote Jung), and because, certainly, one cannot reach human flourishing following the same route as another "(Fermani 2006, p. 271).

The Greek term used by Plato and Aristotle to mean this notion of human fulfilment as individual flourishing, founded on the use of one's own specific resources and capabilities, and on adaptation, each and every time, to different situations, is eupraxia. ${ }^{7}$ Eupraxia is the capability of "playing well" and the skill of realizing- exactly by means of wisdom - a series of good strategies in order to achieve flourishing (eudaimonia).

In this framework, perhaps, we can better understand the fundamental role of wisdom in the use of riches, and also grasp what Plato means when he writes that "virtue does not come from money, but from virtue comes money and all other things to man, both to the individual and to the state" (Apology of Socrates, 30 B 3-5).

In this context it is also possible to explain a very crucial passage from Laws I, $631 \mathrm{C} 4-5$ that argues that riches are certainly counted among the various goods, but they are a kind of

Wealth-no blind (ploutos ou typhlos)... but keen of sight, provided that he has wisdom for companion (epetai phronesei).

Therefore, "wise wealth", that, according to Plato, "has wisdom for companion" constitutes one of the fundamental components of a flourishing life.

This confirms, once again, that while wisdom in all its articulations and functions is essential for attaining a good life, wealth is a necessary but not sufficient instrument for the pursuit of human flourishing.

\subsection{Concluding Remarks: Applying Plato and Aristotle's Thought to Today's Economic Organizations in the Light of the Global Crisis}

Plato and Aristotle's thought, as sketched in the previous sections, can provide us with a useful lens for looking at the present economic situation and evaluating current dominant economic models.

More specifically, we can apply the Platonic-Aristotelian framework to the evaluation of economic models and processes, using the twofold perspective developed in this paper.

On a general level, we can ask ourselves whether the economic models that prevail today are still able to answer the two major questions that economics

\footnotetext{
${ }^{7}$ Aristotle, Nicomachean Ethics I, 8, 1098 b 22. In Plato the same notion is expressed with the term eupragia (see, for instance, Republic, II, 379 B 13).
} 
addressed when it was born, i.e. how it could contribute (1) to individuals' capability to lead a flourishing life; and (2) to social welfare and justice.

At a more detailed level, we can ask ourselves whether the dominant economic models still embrace some principles and values that are ethically and socially grounded.

These questions are even more urgent in the light of the global economic and financial crisis, since this phenomenon is deeply rooted in an economic model based on a logic of accumulation of profit as an end unto itself. Clearly, the ideals behind this model differ greatly from the understanding of economics (and riches) as an instrument for attaining a good life and promoting a fair and just society. This economic model has been accompanied by a blind faith in the "myth" of the invisible hand (one, it is worth noting, that even Adam Smith, its most famous theorist, viewed as working only within a legal and ethical framework) and in automatic mechanisms that should keep the economic system in balance. It is also related to an underestimation of risks and uncertainty, and a strong hostility to overall binding rules, which has lead to deregulation - or, at least, regulation kept as weak as possible - of economics, especially in its financial dimension, from both the legal and the ethical point of view. The underlying idea is that markets always behave efficiently, that financial innovation transfers risk to those who seem to bear it in the best way, that self-regulation works perfectly, and that State intervention has no effect on the economy or can even be dangerous.

Clearly, such an idea fails to take into consideration the fact that markets can suffer the consequences of the burst of financial or speculative bubbles. It does not acknowledge the systemic risk created by excessive unregulated debt, and ignores the fact that a lack of transparency can weaken trust.

In order to clarify this very important point, let us consider the causes of the current crisis. The financial debacle that hit the U.S. in 2007-2008 with the collapse of subprime loans then spread all over the world: in other words, financial globalization lies at the core of the crisis. The financial crisis, in turn, was like the top of an iceberg: excessive debt fed various kinds of speculation, including purely financial forms, among them often dangerous derivatives frequently promoted by unscrupulous financial operators. But, more in general, the crisis grew from a structural overemphasis on the financial side of the economy, which has gained growing importance in the last decades.

In fact, recent decades have been characterised by the financialization of the economy, where financial profit, shareholder value, and short-term outlooks are considered more important than investments in productivity, innovation, and stakeholder value. The financialization of the economy ultimately seems to refer to what Polanyi defined as the "commercialization of money", that is the process of producing and increasing money through money itself, without any mediation of goods or products. This is the excess of an ideology of growth, which is based in turn on a logic of mere accumulation of money as an end unto itself, and where economics is completely disconnected from its ethical and social underpinning.

The consequences of the financial crisis have not been merely financial. They have been (and still are) both economic and social. Among the former, consider the 
turndown of sales and employment in the most important developed countries of the West, and the crisis in or closure of many enterprises. Among the latter, think of the most crucial social effect of the crisis, the increasing inequity of income distribution and, more in general, of wealth, ${ }^{8}$ and the growth of poverty even in affluent countries. All this ties in with the previous considerations: in the last 20-30 years, there has been a shift from incomes to profits, with profits in the financial sector increasing much more quickly than those in other sectors, and incomes in the financial sector increasing far beyond average.

In other words, the crisis has fully shown the very high economic and social costs of economics completely disembedded from the ethical and social dimension, which can thus no longer contribute to individuals' capability to lead a flourishing life, or to social welfare, that is, the fair distribution of wealth and opportunities.

However, the crisis can also be seen as an opportunity, if it is used to abandon failing models and restore or create better ones. In this regard, Plato and Aristotle's thought can provide us with a different and fruitful framework.

More specifically, if we now shift attention from the macro level to the level of economic organizations, the use of Plato and Aristotle's thought as a framework can help us understand ways economic organizations operate to foster more humancentred economic models and practices, to enable individuals to flourish and to work for social welfare.

In particular, Plato and Aristotle's thought helps us to consider an economic organization as a community of persons rather than a mere instrument for profit, and as embedded in the social context and compatible with the fostering of social justice.

In fact, according to a Platonic-Aristotelian perspective, an economic organization would not be a mere aggregate of individuals, but a "cooperative unit", where different people work together in order to attain a common goal: the goal, in turn, does not depend on a sort of sum-ranking of individual efforts, but rather on cooperative interplay. This could be defined the "internal social dimension" of an economic organization, because it regards the cooperation within an economic organization.

At the same time, an economic organization is also embedded in the social context in which it operates: it is a "social construct" (De Gorge 2007), and an instrument for the fostering of social well-being, and thus it should be committed to the service of the community. This could be defined the "external social dimension" of an economic organization, because it regards the cooperation between an economic organization and the community.

In this framework, profit turns out to be not an end unto itself, but only a means through which an economic organization can contribute to fostering the social good by promoting fair exchanges. But in order to fulfill its function, profit needs "measure" and moderation: otherwise, if it is sought in an excessive way, it harms the community, destroys the ties of reciprocity, and prevents the possibility

\footnotetext{
${ }^{8}$ Some analysts even understand the processes of income distribution during the last 30 years as a cause, rather than a consequence, of the crisis (see Reich 2010).
} 
of social justice, as the recent crisis has clearly shown us. In other words, economic organizations have a very important economic and social function, but can fulfill it only insofar as they keep their functional nature in mind and do not aspire to be ends unto themselves. Otherwise, if they evade their responsibility, they produce "riches of the spurious kind", to use Aristotle's words (Politics I, 8, 1275b, 28), with great social costs, as, again, the recent financial-economic crisis clearly shows us.

Moreover, the internal social dimension outlined above (the economic organization as a community of persons rather than a mere instrument for profit) shows us that members of an economic organization should think of themselves as members of the larger community and strive to excel, to bring out what is best in themselves and their shared enterprise. In this view, the economic organization seen as a community is characterized by the search for excellence, the importance of integrity and sound judgment. All this can lead to a more cooperative and humane vision of business, according to which an economic organization could foster the development of human virtues and therefore take into account everyone's need to grow as a person through human virtues (Melé 2003, p. 85).

As Plato and Aristotle teach us, growing as persons requires the capability to act virtuously, and virtue in turn demands self-moderation and self-knowledge. At the same time, human flourishing also requires the capability to engage in social relationships and friendships, since eudaimonia, as we have seen, is deeply social. All this ultimately refers to the need for practical wisdom. Wisdom, in fact, is the cornerstone of virtuous action and life. As we mentioned above, human beings need examples of real people who form themselves in an excellent way and act virtuously. If we apply these considerations to economic organizations, we see the fundamental role of leaders, who have the responsibility to lead by example and thus to contribute to an environment in which all members of an organization have the opportunity to realise their own potential, and thus to flourish, seeking excellence and contributing to the common good.

In conclusion, we can state that the capability of leading by example, judging and acting wisely, is itself a way of restoring the values and "anthropological types" that allowed the working of capitalism itself at its origins: in fact these values and "anthropological types" embedded economic activity in ethics and bound it to the society in which it functioned. Such "wise leaders" are very much needed today, especially in the light of the global crisis: in fact, in such a difficult situation, having examples of real people who act virtuously and excel in practical wisdom may help even more (or at least not less) than laws do.

\section{References}

\section{Lexica}

Radice, R., \& Bombacigno, R. (2003). Plato, with CD-ROM. Milan: Biblia.

Radice, R., \& Bombacigno, R. (2005). Aristoteles, with CD-ROM. Milan: Biblia. 


\section{Plato and Aristotle's Works}

All direct quotes of the works by Plato and Aristotle come from the The Loeb Classical Library. Cambridge (MA.) - London: Harvard University Press.

\section{Critical Studies}

Collins, D. (1987). Aristotle and business. Journal of Business Ethics, 6(7), 567-572.

Cooper, J. M. (1975). Reason and human good in Aristotle. Cambridge, MA: Harvard University Press.

Crockett, C. (2005). The cultural paradigm of virtue. Journal of Business Ethics, 62(2), 191-208.

De Gorge, R. T. (2007). The corporation as a social construct. Notizie di Politeia, 85(86), 15-24.

De Heer, C. (1968). Makar-Eudaimon-Olbios-Eutyches. A Study of the semantic field denoting Happiness in ancient Greek to the end of the 5th century B.C. Amsterdam: University of Western Australia Press.

Fermani, A. (2006). Vita felice umana. In dialogo con Platone e Aristotele. Macerata: Eum.

Finley, M. I. (1973). The ancient economy. Berkley-Los Angeles: University of California Press.

Garret, B. (1998). Personal identity and self-consciousness. London: Routledge.

Giovanola, B. (2009). Re-thinking the anthropological and ethical foundation of economics and business: human richness and capabilities enhancement. Journal of Business Ethics, 88(3), 431-444. doi:10.1007//s10551-009-0126-9.

Hadreas, P. (2002). Aristotle on the vices and virtues of wealth. Journal of Business Ethics, 39(4), 361-376.

Koehn, D. (1995). A role for virtue ethics in the analysis of business practice. Business Ethics Quarterly, 5(3), 533-539.

Lötter, H. P. P. (2003). The significance of poverty and wealth in Plato's Republic. South African Journal of Philosophy, 22(3), 189-206.

Meikle, S. (1996). Aristotle on business. The Classical Quarterly, New Series, 46(1), 138-151.

Melé, D. (2003). The Challenge of humanistic management. Journal of Business Ethics, 44(1), $77-88$.

Napolitano Valditara, L.M. (2012). The Knowledge of the soul. Plato and the problem of selfawareness. In M. Migliori, L.M. Napolitano Valditara, \& A. Fermani (Eds.), Inner life and soul. Psychē in Plato. Sankt Augustin: Academia Verlag, 151-184.

North, H. (1966). 'Sophrosyne' : Self-knowledge and self-restraint in Greek literature. Ithaca-New York: Cornell University Press.

Renaud, F. (2012). Self-knowledge in the first alcibiade and in the commentary of Olympiodorus. In M. Migliori, L.M. Napolitano Valditara, \& A. Fermani (Eds.), Inner life and soul. Psychë in Plato. Sankt Augustin: Academia Verlag, 207-223.

Reich, R. B. (2010). Aftershock. The next economy and America's future. New York: Knopf.

Santas, G. (2001). Goodness and justice. Plato, Aristotle, and the moderns. Oxford: Blackwell.

Schofield, M. (1993). Plato on the economy. In H.H. Mogens (Ed.), The ancient Greek city-state: Symposium on the Occasion of the 250th anniversary of the Royal Danish Academy of sciences and letters, (pp. 183-196). Copenhagen: The Royal Danish Academy of Sciences and Letters.

Sen, A. (1987). On ethics and economics. Oxford: Blackwell.

Solomon, R. (2004). Aristotle, ethics and business organizations. Organization Studies, 25(6), 1021-1043. 